\title{
ESTRUTURA E DINÂMICA DAS PAISAGENS DO BAIRRO SÍTIO CERCADO - CURITIBA, PR
}

\author{
Mariane Félix da Rocha ${ }^{1}$, João Carlos Nucci², Simone Valaski ${ }^{3}$
}

\section{RESUMO}

O presente trabalho teve como objetivo mapear a cobertura do solo do bairro Sítio Cercado (Curitiba, PR) e apresentar uma chave classificatória das unidades de paisagens mapeadas de modo a facilitar a interpretação das mesmas, utilizando um método que se baseia na identificação da estrutura da paisagem (cobertura do solo) e em inferências em relação à sua dinâmica e qualidade ambiental. Além disso, elaborou-se um mapa indicando a estrutura e dinâmica das paisagens do bairro, para o melhor entendimento dos processos e das consequências das decisões tomadas sobre essas paisagens. As informações foram apresentadas de forma simplificada, com o uso de fotografias, imagens de satélite, desenhos e textos explicativos simples, a fim de facilitar a compreensão e favorecer, dessa forma, a participação popular no planejamento. Como resultado, obteve-se que no bairro Sítio Cercado predominam edificações baixas sem jardim, com solo bastante impermeabilizado, com poucos espaços não edificados, sobretudo em áreas próximas a rios e pouca vegetação, aspectos que indicam para uma baixa qualidade ambiental.

Palavras-chave: Planejamento participativo; Qualidade ambiental urbana; Cobertura do solo.

Recebido em 22.12.2013 e aceito em 15.05.2015

1 Graduada em Geografia e Mestranda em Geografia pela Universidade Federal do Paraná (Departamento de Geografia), Curitiba - PR.mfr1306@yahoo.com.br

2 Graduado em Ciências Biológicas (IB-USP) e Doutor em Geografia Física pela Universidade de São Paulo. Professor do Departamento de Geografia da Universidade Federal do Paraná, Curitiba - PR. jcnucci@gmail.com

3 Graduada em Geografia e Doutora em Geografia pela Universidade Federal do Paraná (Departamento de Geografia), Curitiba - PR. Professora do Setor de Educação Profissional e Tecnológica (SEPT-UFPR) simonevalaski@ig.com.br 


\section{STRUCTURE AND DYNAMICS OF LANDSCAPES OF SÍTIO CERCADO DISTRICT, CURITIBA - PR}

\section{ABSTRACT}

The present research aimed to map the land cover in the Sítio Cercado district (Curitiba, PR) and presents a classificatory key of landscape units mapped in order to facilitate the interpretation of the district, using a method that is based in identifying the landscape structure (land cover) and inferences regarding their dynamics and environmental quality. Besides, a map was elaborated indicating the structure and dynamics of the landscape of the district, to a better understanding of the processes and consequences of decisions taken on these landscapes. The information was presented in a simplified way, using photographs, satellite images, drawings and explanatory texts to facilitate the understanding of this information, favoring thus population participation in planning. As a result, it was found that in the Sítio Cercado district predominate low buildings without garden, with impermeable ground and few non-built up spaces, especially in areas close to rivers and little vegetation, aspects that indicate to a low environmental quality.

Keywords: Participatory planning; Urban environmental quality; Land cover.

\section{INTRODUÇÃO}

O uso e a cobertura do solo que caracterizam as áreas urbanizadas exercem grande influência na qualidade ambiental urbana.

Sukopp et al. (1979) afirmam que "(...) mudanças na temperatura do ar, umidade e velocidade dos ventos causados por um clima urbano podem basicamente ser correlacionados com a densidade de construção, grau de impermeabilização do solo e proporção de áreas verdes". Esta afirmação remete à importância de se estudar como o solo de uma cidade está sendo utilizado e estruturado, ou seja, a qualidade ambiental está diretamente associada ao uso e a cobertura do solo urbano (HAMBURGER; FORESTI, 1997). 
Nucci (2008) apresentou os seguintes indicadores de qualidade ambiental urbana: clima e poluição atmosférica, água (enchentes e abastecimento), resíduos (líquidos e sólidos), poluição sonora e visual, cobertura vegetal, áreas verdes e espaços livres, espaços livres e recreação, verticalização e densidade populacional. Estes indicadores estão, direta ou indiretamente, relacionados ao uso e cobertura do solo urbano e são influenciados, sobretudo, pelo aumento da superfície impermeabilizada por vias e outras construções, aumento dos gabaritos das edificações e ausência de cobertura vegetal. Tais situações resultam, dentre outros problemas, na redução da infiltração de água no solo e consequente aumento do escoamento superficial (runoff), bem como no aumento das temperaturas em virtude da alta capacidade térmica dos materiais utilizados.

Antunes e Figueiró (2011) são favoráveis a uma concepção mais dinâmica e complexa da natureza em áreas urbanas em substituição aos modelos rígidos e estruturados e concordam que uma das categorias fundamentais a ser compreendida na paisagem é justamente sua estrutura, uma vez que os processos (o funcionamento ou a dinâmica) aparentam clara subordinação à estrutura da paisagem, o que também está de acordo com a opinião de Alberti $(2007,2008)$.

No entanto, o planejador não deve ser um "profissional ditador que determina por si só o desenho dos espaços" (PRONSATO, 2005, p. 32). É necessário considerar, também, os anseios da população.

Ao me referir à abordagem participativa no projeto de espaços públicos, procuro entendê-la como processo que inter-relaciona a atividade do arquiteto e de outros profissionais que estudam e projetam espaços, os 'espaciólogos' no sentido emprestado por Milton Santos a essa palavra, com as pessoas que usufruirão do lugar, seus sonhos e desejos, objetos do projeto (PRONSATO, 2005, p. 123).

Almeida (1993) ainda inclui que no planejamento participativo a população deve dispor de "mecanismos eficazes para influenciar a condução da máquina pública, ter acesso aos meios de comunicação e dispor de informações", o que vai além da mera consulta à população sobre determinados programas, sem que esta tenha tido acesso à formulação dos mesmos.

Com base nisso, Valaski (2013) avaliou o material cartográfico disponibilizado no site do Instituto de Pesquisa e Planejamento Urbano de Curitiba (IPPUC), a fim de analisar se esse material oferece informações acessíveis e de qualidade sobre a estrutura da paisagem do município, para que a população possa efetivamente entender os processos e as consequências das decisões tomadas sobre as paisagens da cidade e, dessa forma, participar do processo de planejamento do município. A análise dos materiais cartográficos mostrou que, a despeito da grande quantidade de informação disponibilizada no site do IPPUC. 
a falta de mapas em escala de detalhe (1:5.000), a dificuldade que o usuário tem de localizar e juntar informações distintas, a falta de informações sobre metodologias e conceitos, a falta de padronização na apresentação dos mapas e das fontes, conclui-se que os mapas disponibilizados no site do IPPUC não fornecem a possibilidade de entendimento dos processos que ocorrem na paisagem do município de Curitiba (VALASKI, 2013, p. 136).

Valaski (2013), então, propôs um mapeamento da cobertura do solo da cidade, baseado em critérios para avaliação da qualidade ambiental, propostos por Nucci (2008), apresentado conjuntamente a uma chave classificatória das paisagens.

Uma das bases teóricas do trabalho de Valaski (2013) é a cartografia de biótopos. De acordo com Blanes (2006) biótopo, em seu conceito clássico, pode ser definido como a área ocupada por uma biocenose ou uma parcela da superfície ocupada por um conjunto de elementos da fauna e flora, num determinado tempo, porém a autora também inclui o componente antrópico, além do biológico e físico. Denominam-se biótopos como unidades de paisagem ou zonas homogêneas e, portanto, no mapeamento de biótopos, a conotação biológica do termo pode não ser a ideal, pois aspectos físicos e antrópicos também podem ser considerados, no entanto, a popularização internacional do termo biótopo justificaria sua adoção.

Para Cadaval Bedê et al. (1997), a utilização da cartografia de biótopos permite classificar tanto as paisagens naturais quanto aquelas com variados graus de intervenção humana (áreas rurais e urbanas).

Como parâmetros diferenciadores dos biótopos são utilizadas características da estrutura (suporte físico), uso e biota. A importância do mapeamento de biótopos no meio urbano diz respeito à grande heterogeneidade da superfície urbana, pois há diferenças quanto ao tipo de edificação predominante, seu grau de adensamento e verticalização, tipo e intensidade de usos, grau de impermeabilização e outros (CADAVAL BEDÊ et al., 1997).

O objetivo principal do mapeamento de biótopos é o "fornecimento de bases para a indicação de medidas de melhoria da qualidade ambiental" (CADAVAL BEDÊ et al., 1997, p. 4), principalmente por meio da elaboração de diagnósticos, realizados por "desmembramento de uma determinada superfície de estudos em unidades cartográficas de uso e estrutura ambiental semelhantes, descrevendo exaustivamente suas características" (CADAVAL BEDÊ et al., 1997, p. 4). Também pode fornecer um conjunto de informações básicas voltadas a um planejamento futuro que, se elaborado em versões populares, tornam-se acessíveis ao público leigo, possibilitando sua participação (CADAVAL BEDÊ et al., 1997).

Com base na cartografia de biótopos e com vistas à participação popular, esse trabalho teve como objetivo elaborar um mapa da cobertura do solo do bairro Sítio Cercado 
(Curitiba/PR) e organizar uma chave classificatória com a descrição e ilustração da estrutura e dinâmica das paisagens identificadas. Sendo assim, tanto o mapa quanto a chave classificatória foram elaborados com o intuito de facilitar a interpretação da população local sobre a estrutura e dinâmica das paisagens do bairro, possibilitando sua participação no planejamento dos destinos do município.

\section{MATERIAIS E MÉTODOS}

O bairro Sítio Cercado (figura 1), com 115.525 habitantes, é o terceiro bairro de maior densidade demográfica do município, ou seja, 103,15 hab/ha (IPPUC, 2010) e possui, apenas, 3,05 $\mathrm{m}^{2}$ de área verde por habitante ou $2,81 \%$ da área do bairro cobertos por áreas verdes (IPPUC, 2000).

Figura 1. Localização do bairro Sítio Cercado

Figure 1. Location of Sítio Cercado district

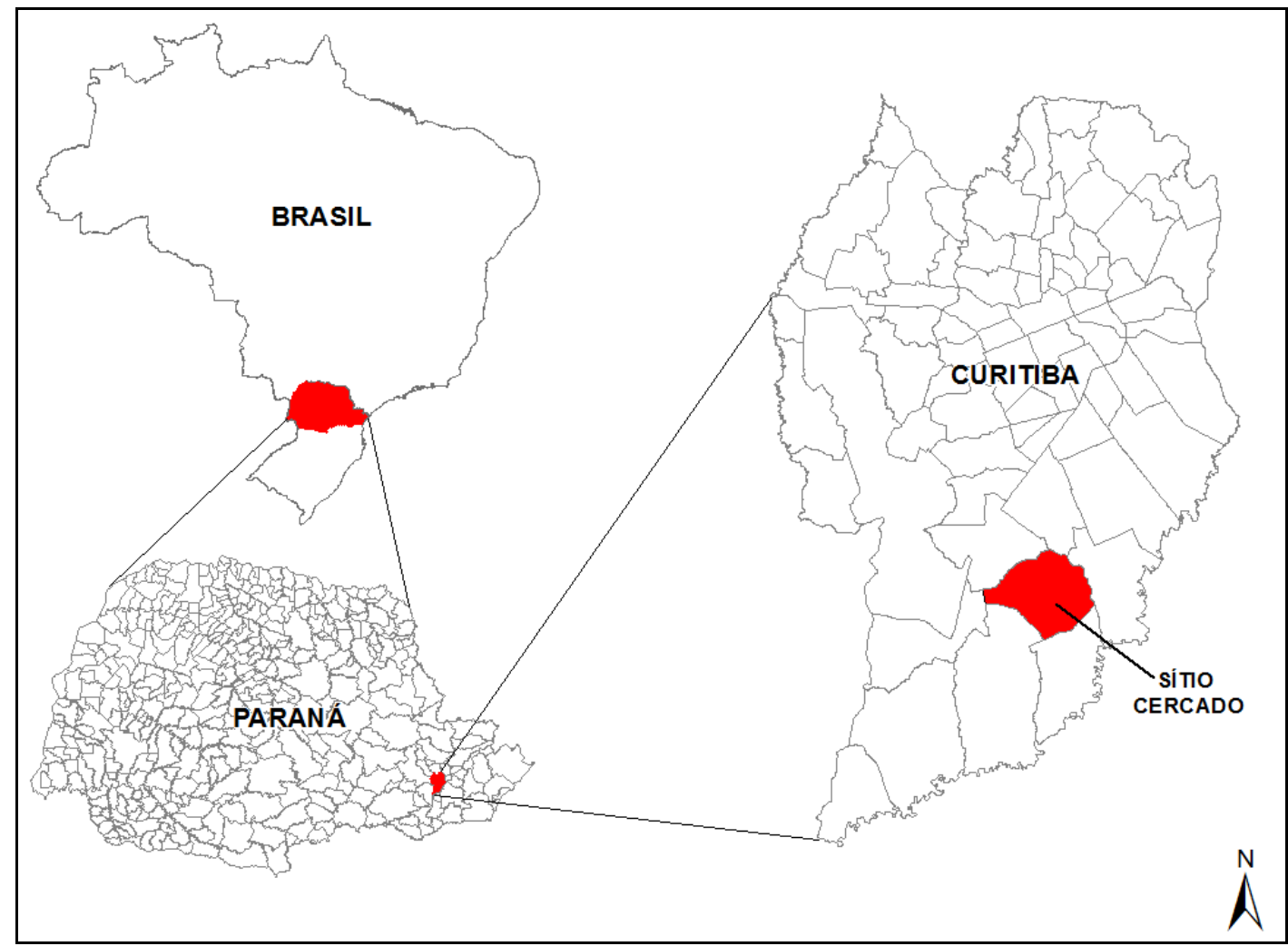

Org.: O autor (2013) 
Para a elaboração do mapeamento da cobertura do solo do bairro, na escala final de 1:25.000, foram utilizadas como base as categorias apresentadas na figura 2 , sendo feita a classificação de todo o bairro quadra por quadra, no software QuantumGIS, com base na análise das imagens disponibilizadas no site Google Maps, do ano de 2013, na escala aproximada de 1:5.000 e com base cartográfica (shapes de ruas, quadras e limites políticos) cedida pelo IPPUC (Instituto de Pesquisa e Planejamento Urbano de Curitiba), do ano de 2012, de escala 1:10.000. Cada quadra foi analisada na imagem de satélite, definida sua categoria e classificada no mapa e, em caso de dúvida ou para a contagem de pavimentos de prédios, a ferramenta Google Street View (imagens horizontais) foi utilizada. As quadras que apresentaram mais de uma categoria foram divididas e cada parte classificada separadamente. As cores e organização da legenda e o layout do mapa foram baseadas em Valaski (2013).

Figura 2. Legenda-base para a classificação da cobertura do solo

Figure 2. Key for the land cover classification

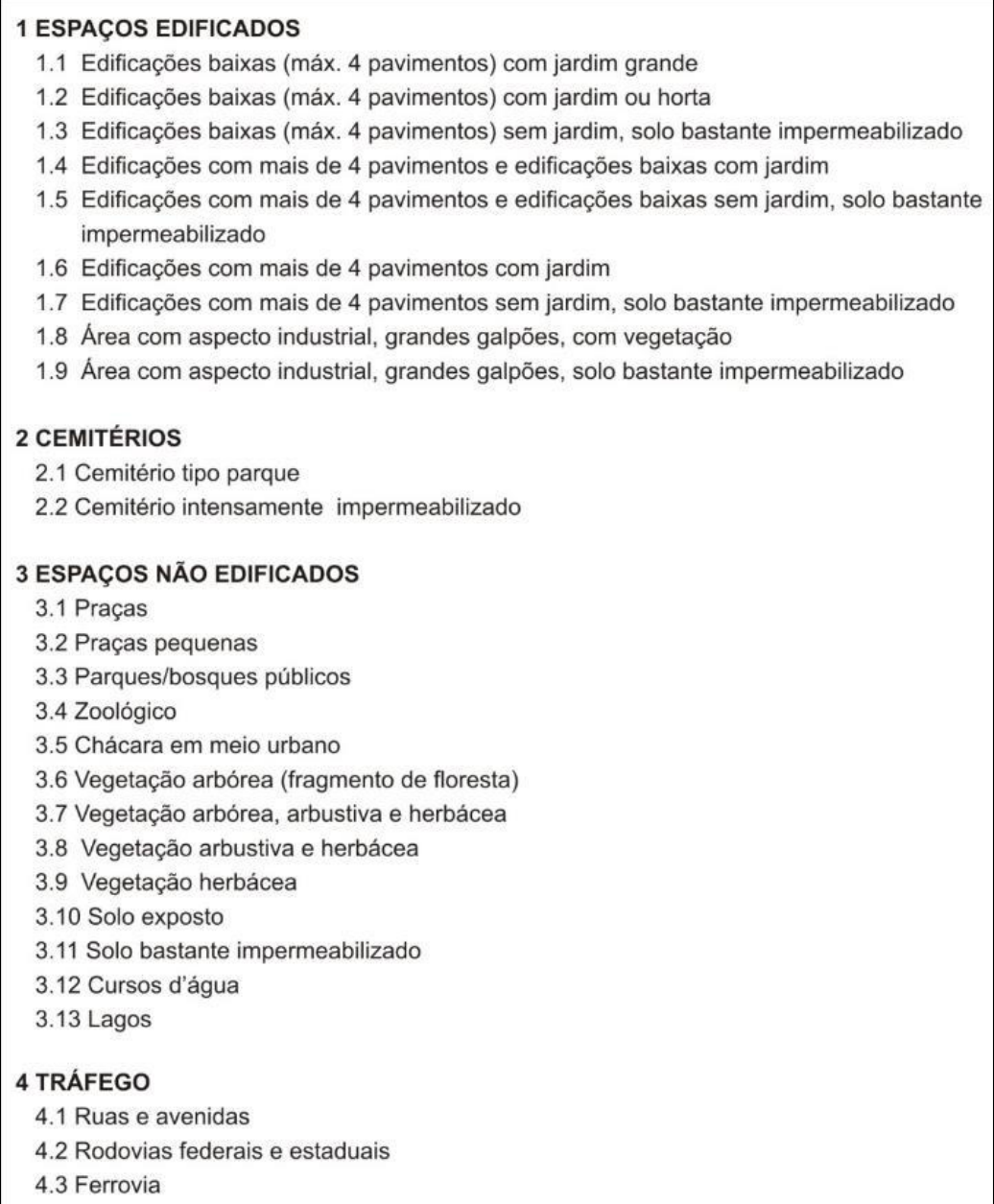


O método desenvolvido por Valaski (2013), de mapeamento da estrutura das paisagens urbanas e inferência de suas respectivas dinâmicas, foi utilizado para identificar e classificar as paisagens do bairro Sítio Cercado, bem como para elaborar a chave classificatória, na forma de um quadro-legenda.

A legenda-base utilizada no mapeamento foi a mesma que Valaski desenvolveu em sua tese, que teve como área de estudo um transecto norte-sul do município de Curitiba, passando pelo bairro Centro, com uma faixa de, aproximadamente, $400 \mathrm{~m}$ de largura. $\mathrm{A}$ intenção foi a de abranger a maior diversidade possível de estruturas da paisagem. A legenda-base foi adaptada para a realidade do bairro sendo incluída a classe 5 Transportes, na qual se inclui a categoria 5.1- Terminais de ônibus municipais. Também foram substituídos os termos "áreas com aspecto industrial, grandes galpões", presentes nos itens 1.8 e 1.9, por "grandes edificações".

As categorias de cobertura do solo escolhidas por Valaski (2013) consideram sua relação com a qualidade ambiental urbana, conforme método desenvolvido por Nucci (2008). Na categoria espaços edificados, foram analisadas a altura das edificações (sendo consideradas edificações baixas as com máximo de 4 pavimentos), uma vez que edificações mais altas contribuem mais negativamente para a qualidade ambiental comparadas às edificações baixas; e a presença ou não de vegetação (com jardim grande, com jardim/ horta ou sem jardim; com vegetação ou solo bastante impermeabilizado para as grandes edificações), pois áreas permeáveis e com vegetação contribuem positivamente com a qualidade ambiental (VALASKI, 2013).

A vegetação também foi considerada na categoria cemitério, separado em cemitério tipo parque e cemitério intensamente impermeabilizado. Os espaços não edificados são compostos por praças, praças pequenas, parques/bosques públicos, zoológico, chácara em meio urbano, vegetação arbórea (fragmento de floresta), vegetação arbórea, arbustiva e herbácea, vegetação arbustiva e herbácea, vegetação herbácea, solo exposto, solo bastante impermeabilizado, cursos d'água e lagos. A categoria tráfego engloba ruas e avenidas, rodovias federais/estaduais e ferrovia. Com base nisso, Valaski (2013) inferiu uma correlação entre a cobertura do solo e a qualidade ambiental, sendo que áreas com mais vegetação, permeáveis, sem edificações ou com predomínio de edificações mais baixas contribuem mais positivamente com a qualidade ambiental urbana (figura 3 ).

A fim de facilitar a compreensão do mapa por parte da população local, facilitando a interpretação da paisagem classificada e para inferir a dinâmica com base na estrutura da paisagem, foi confeccionada uma chave classificatória, igualmente baseada em Valaski (2013). A chave classificatória é composta de imagem de satélite (do site Google Maps), um 
esquema (desenho) representativo da estrutura da paisagem, uma fotografia (do Google Street View) e um texto explicativo simples da estrutura e da dinâmica de cada paisagem/categoria da legenda, exceto as categorias de tráfego e transporte e, dos espaços não edificados, os cursos d'água e rios. Somente foram incluídas na chave classificatória as categorias que apareceram no mapa.

Figura 3. Relação entre os espaços edificados e a qualidade ambiental urbana Figure 3. Relation between the buildings and urban environmental quality

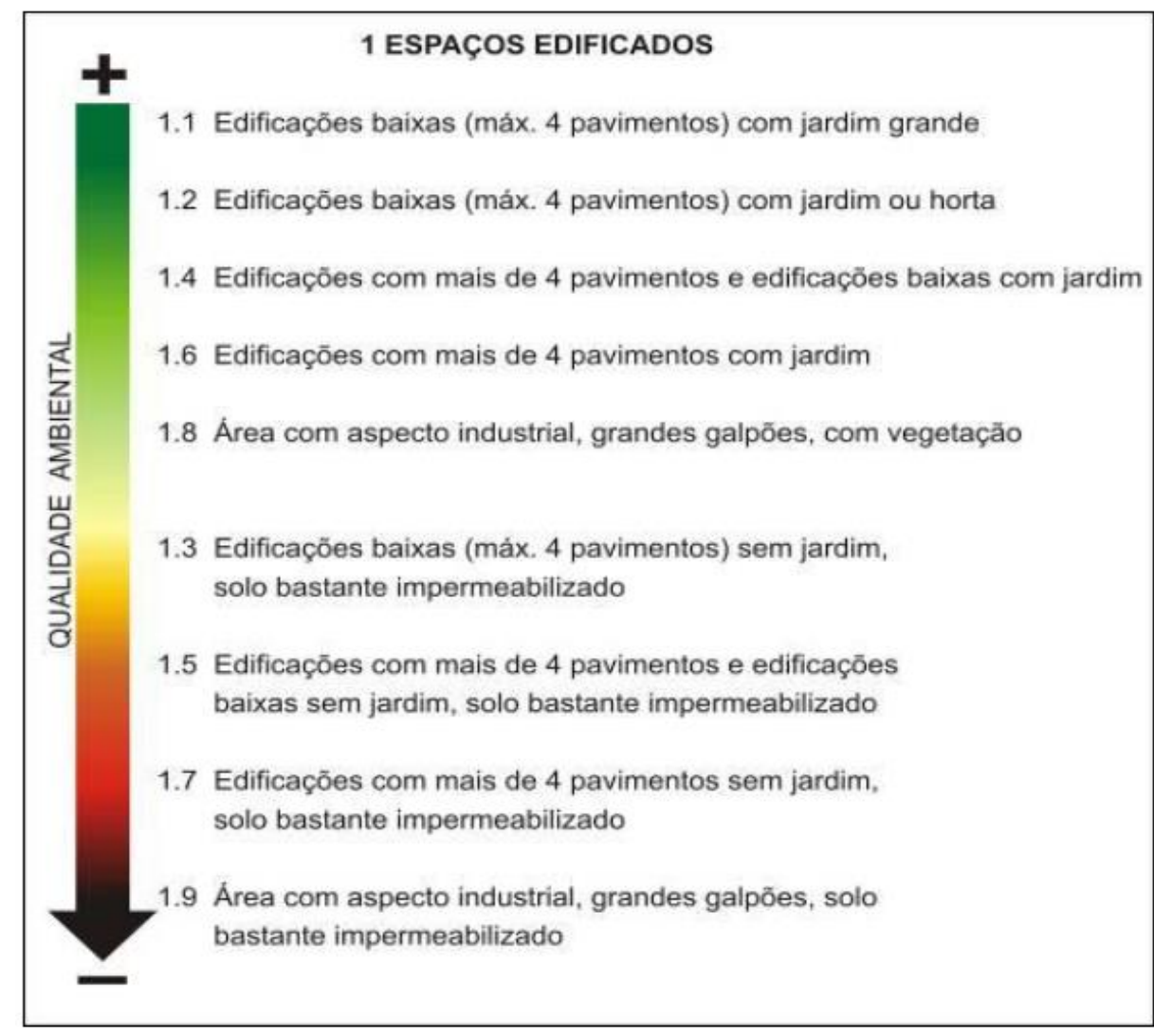

Fonte: Valaski (2013)

\section{RESULTADOS E DISCUSSÃO}

Como resultado do mapeamento, obteve-se que no bairro Sítio Cercado predominam edificações baixas (máximo 4 pavimentos) sem jardim, com solo bastante impermeabilizado, o que não contribui para a melhora da qualidade ambiental do bairro.

Na figura 4 estão espacializadas todas as categorias encontradas no bairro. 
Figura 4. Mapeamento da cobertura do solo do bairro Sítio Cercado, Curitiba - PR

Figure 4. Mapping of land cover in the Sítio Cercado district, Curitiba - PR

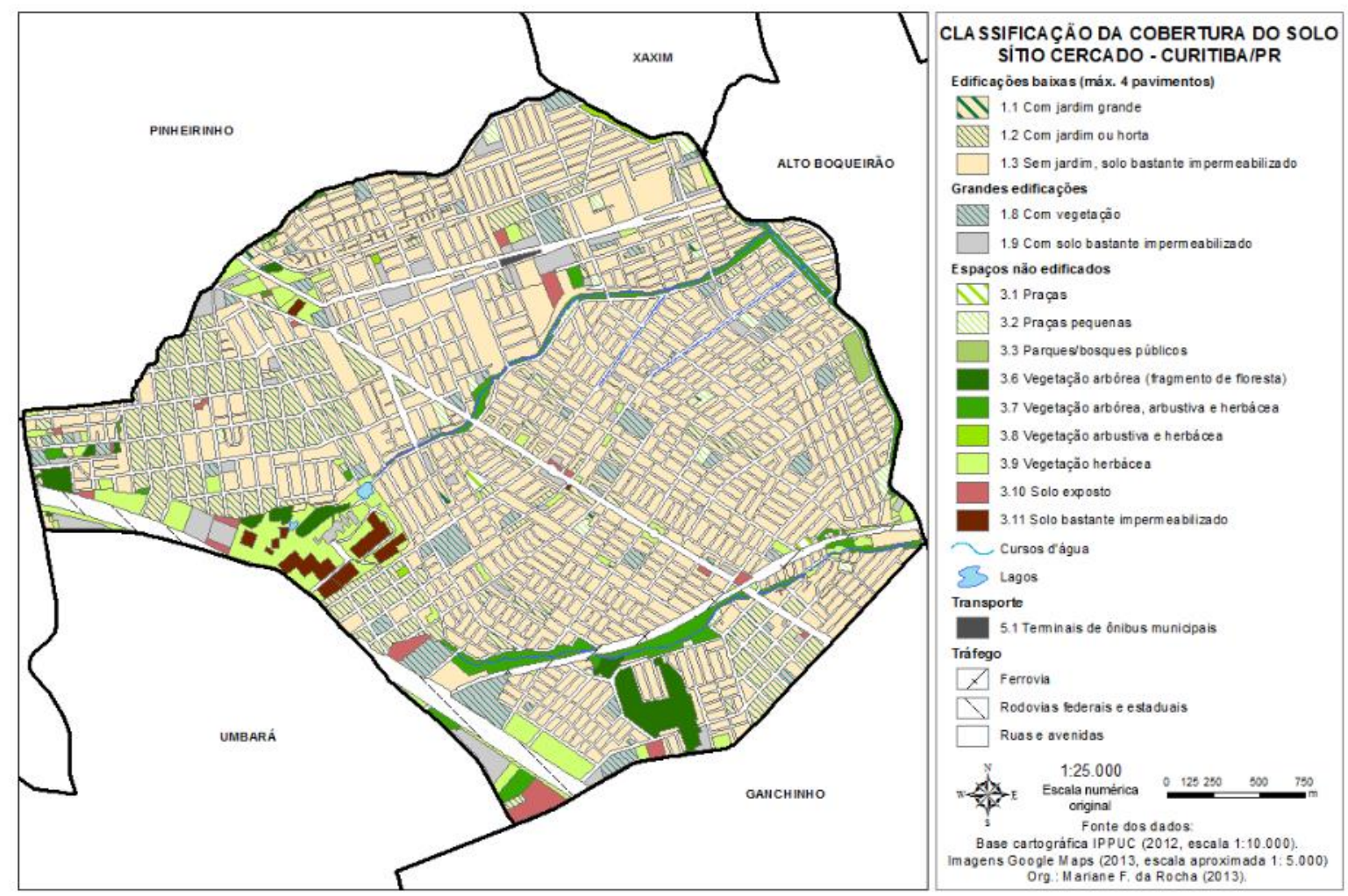

Org.: O autor (2013).

A chave classificatória, ilustrando as categorias de legenda presentes no mapa e demonstrando a estrutura e dinâmica das paisagens do bairro, é apresentada nas figuras $5 a$ a $5 d$.

As categorias edificações com mais de 4 pavimentos e edificações baixas com jardim, edificações com mais de 4 pavimentos e edificações baixas sem jardim - solo bastante impermeabilizado, edificações com mais de 4 pavimentos com jardim, edificações com mais de 4 pavimentos sem jardim - solo bastante impermeabilizado, cemitérios, zoológico e chácara em meio urbano não apareceram como paisagens do bairro e, portanto, não são descritas na chave classificatória. 
Figura 5a. Chave classificatória com inferências da dinâmica da paisagem: edificações baixas

Figure 5a. Classificatory key with inferences of landscape dynamics: low buildings

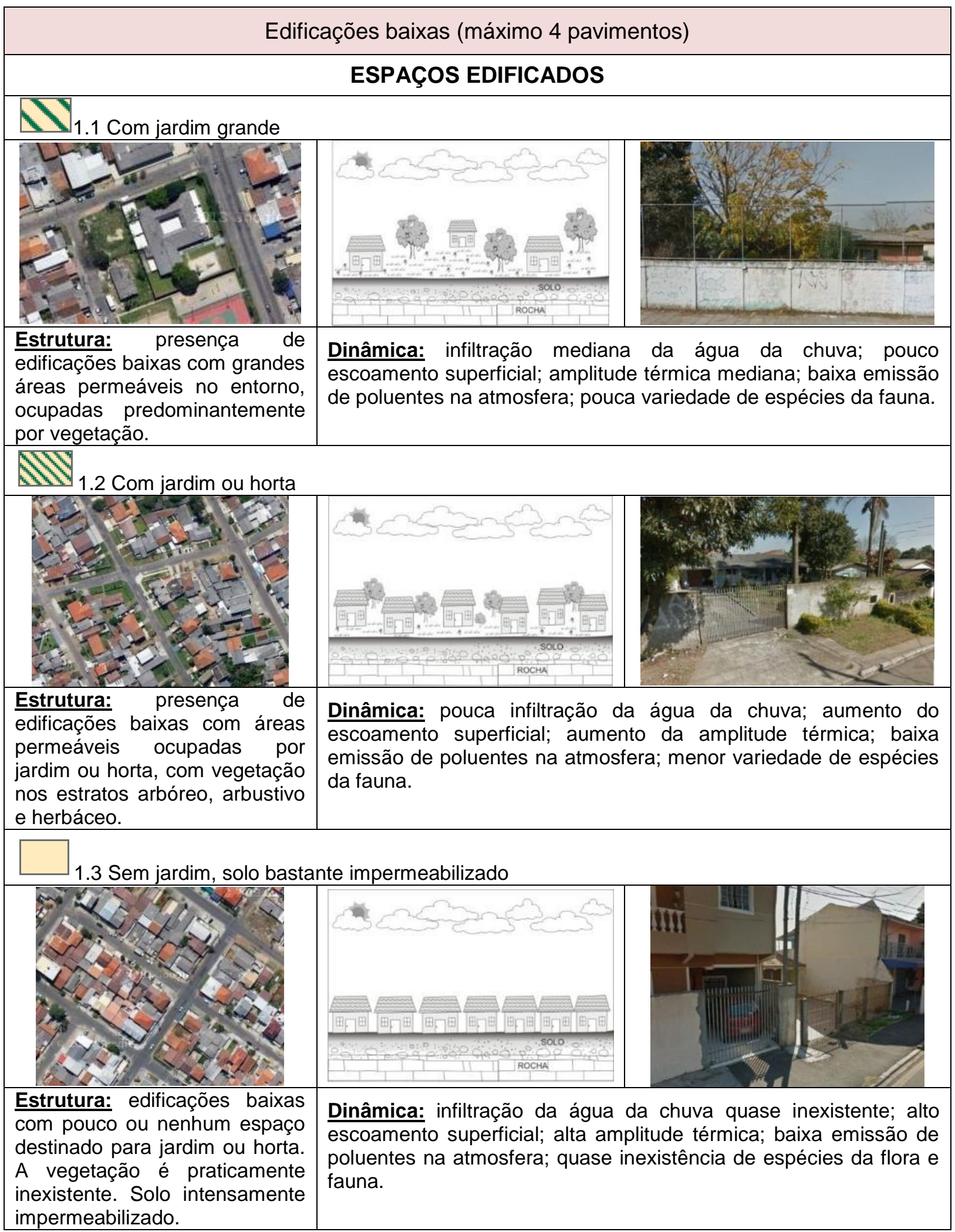

Fonte: Valaski (2013). Org.: O autor (2013). 
Figura 5b. Chave classificatória com inferências da dinâmica da paisagem: grandes edificações

Figure 5b. Classificatory key with inferences of landscape dynamics: big buildings

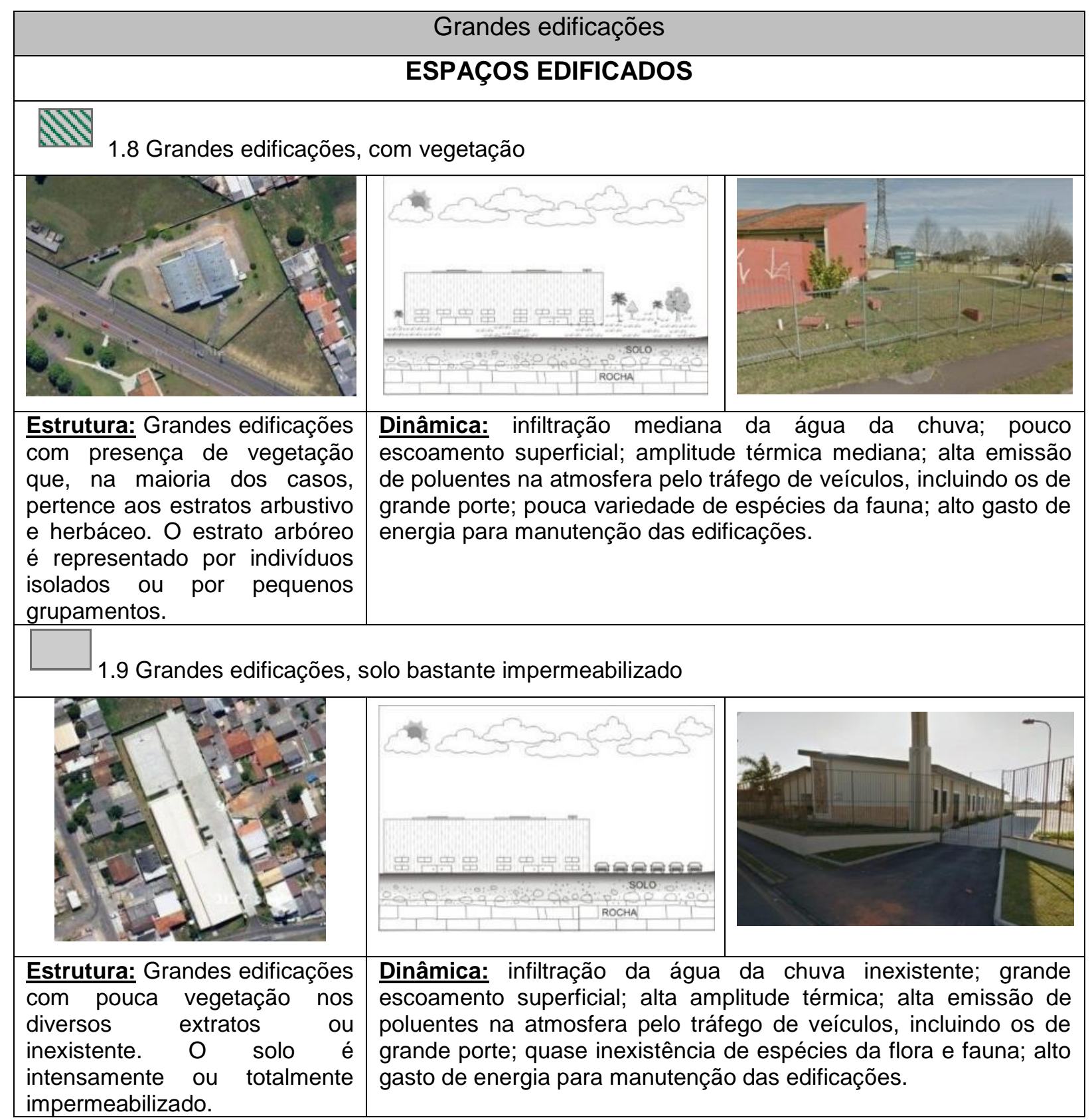

Fonte: Valaski (2013). Org.: O autor (2013). 
Figura 5c. Chave classificatória com inferências da dinâmica da paisagem: espaços não edificados

Figure 5c. Classificatory key with inferences of landscape dynamics: non-built up spaces

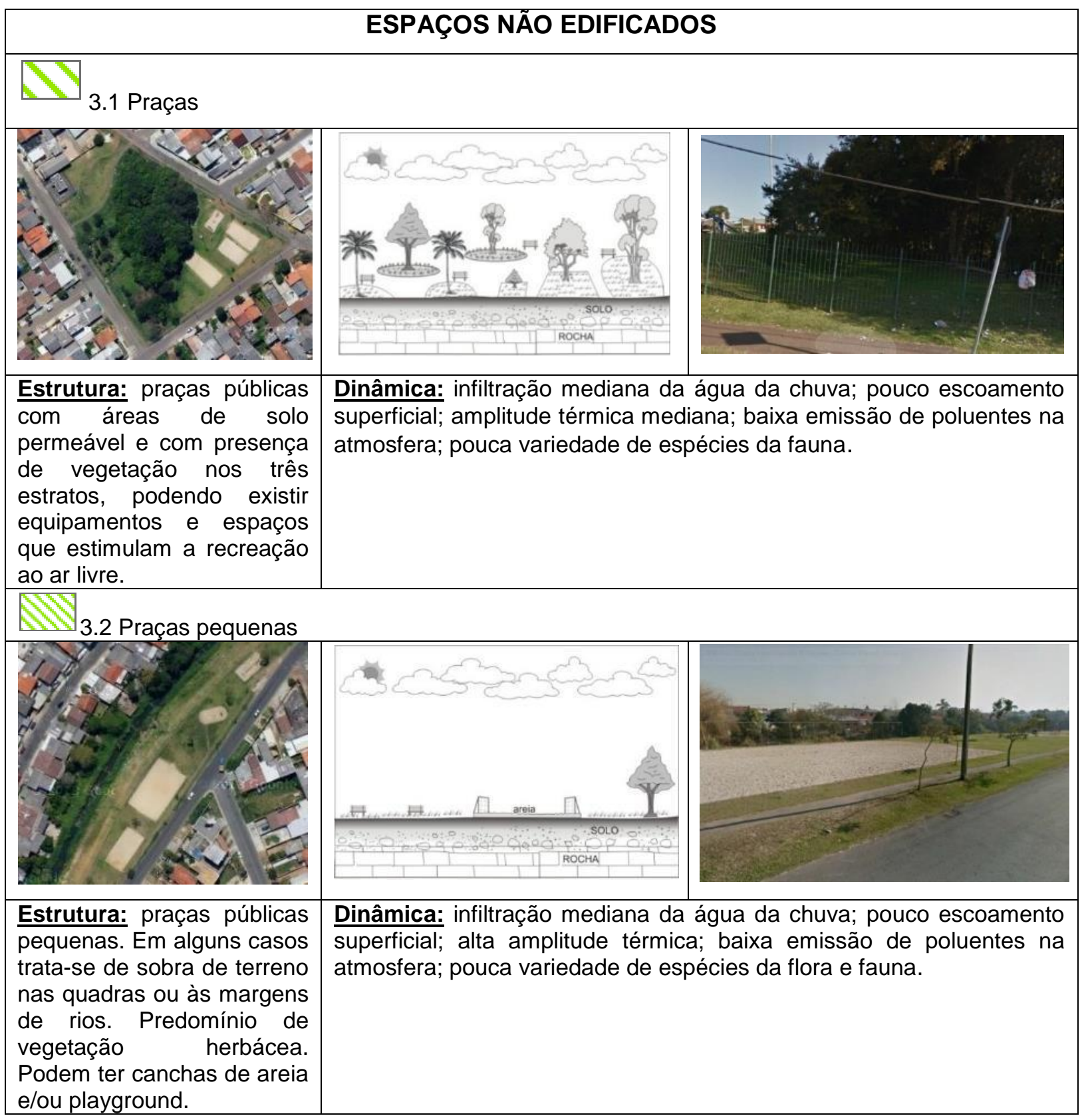


Continuação...

\subsection{Parques/bosques públicos}

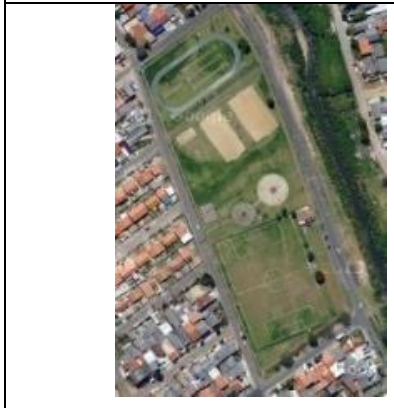

Estrutura: parques bosques públicos. Grande área com solo permeável e presença de vegetação nos três estratos. Possui equipamentos e espaços que estimulam a recreação ao ar livre. Podem ter corpos hídricos.
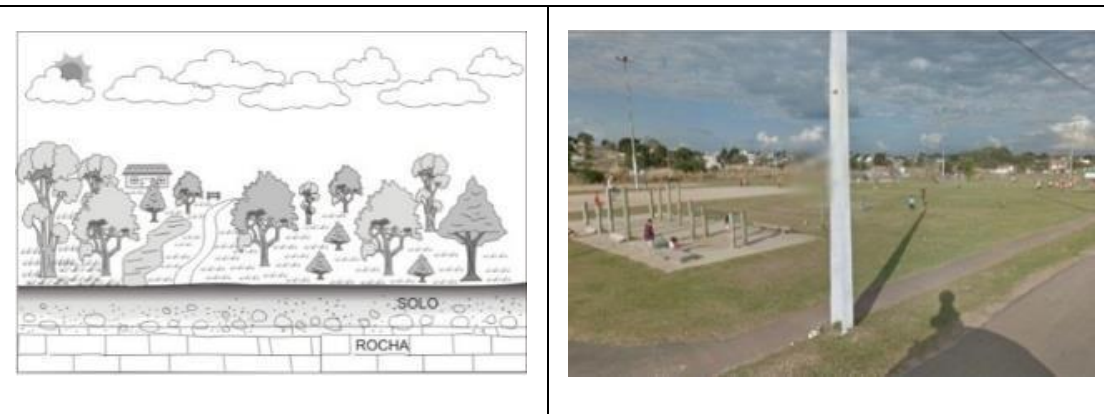

Dinâmica: alta infiltração da água da chuva; escoamento superficial muito baixo; baixa amplitude térmica; baixa emissão de poluentes na atmosfera; maior variedade de espécies da flora e fauna.

3.6 Vegetação arbórea (fragmento de vegetação)

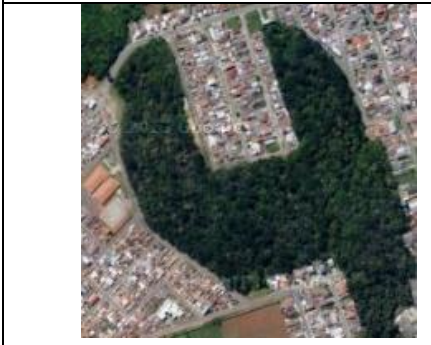

Estrutura: terreno sem edificações, permeável, com predomínio de vegetação arbórea. São grupamentos de árvores, caracterizando um fragmento de floresta.
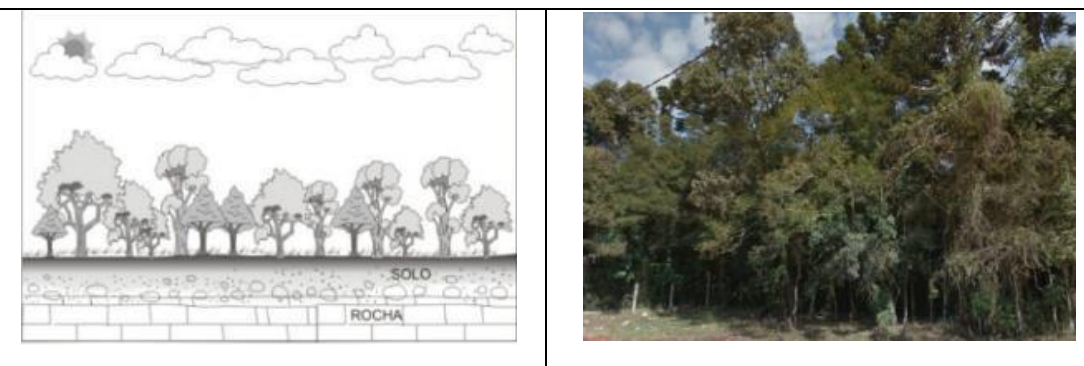

Dinâmica: alta infiltração da água da chuva; escoamento superficial muito baixo; baixa amplitude térmica; baixa emissão de poluentes na atmosfera; grande variedade de espécies da flora e da fauna; alta taxa de evapotranspiração.

\subsection{Vegetação arbórea, arbustiva e herbácea}

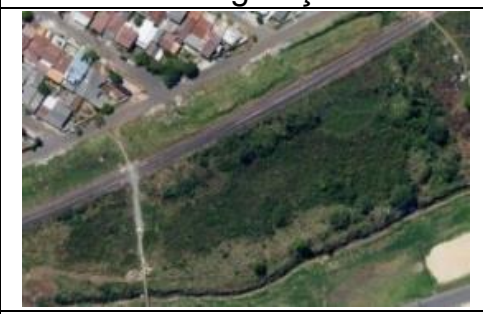

Estrutura: terreno sem edificações, permeável, com vegetação nos três estratos. A vegetação arbórea é um pouco esparsa, não formando fragmentos
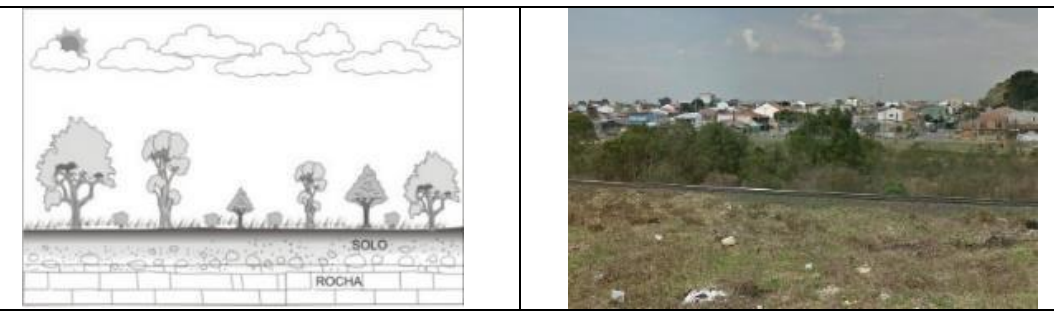

Dinâmica: diminuição da infiltração da água da chuva; escoamento superficial baixo; baixa amplitude térmica; baixa emissão de poluentes na atmosfera; diminuição da variedade de espécies da flora e da fauna; diminuição da taxa de evapotranspiração. 
Continuação...

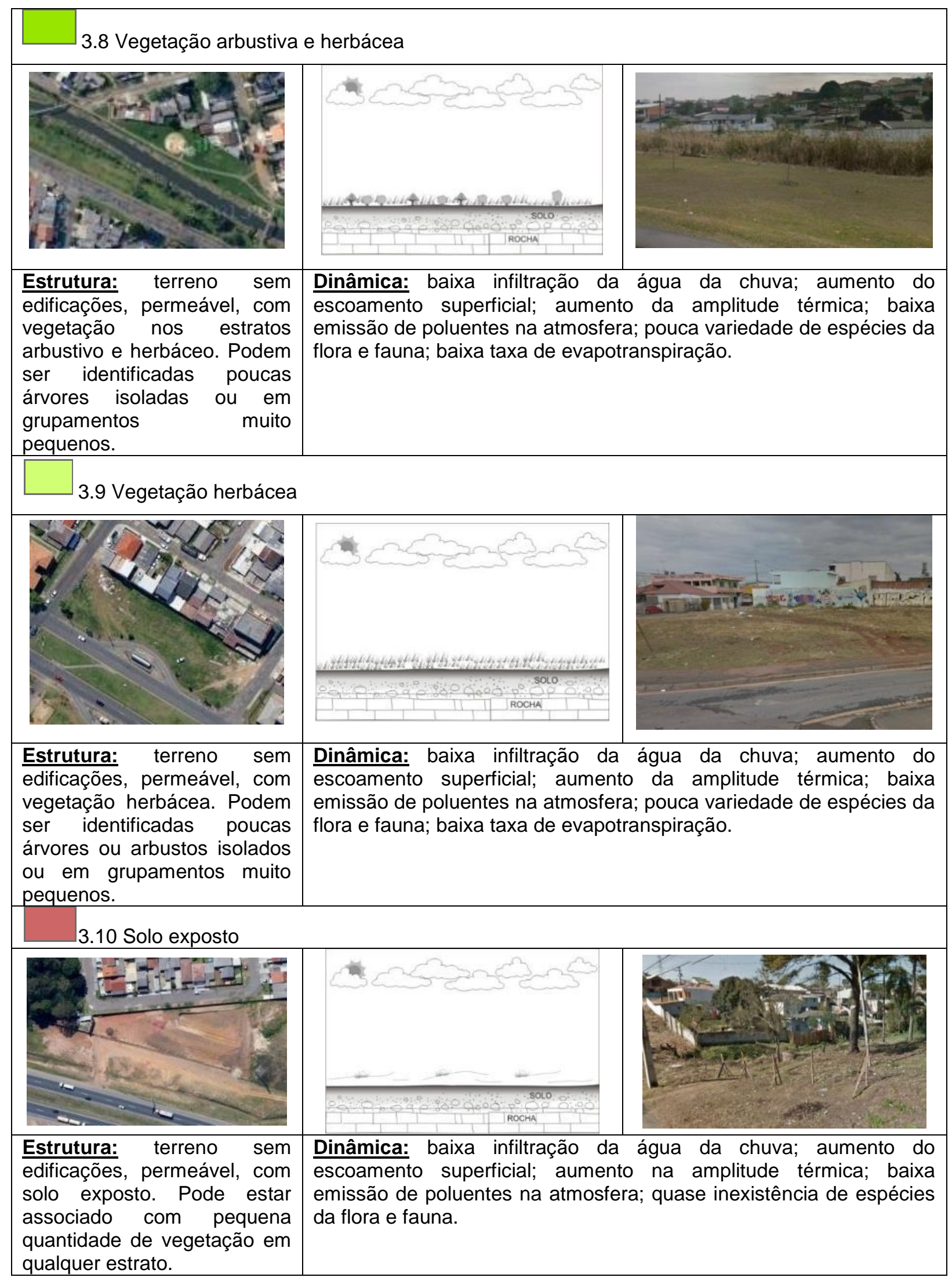


Continuação...

3.11 Solo totalmente impermeabilizado

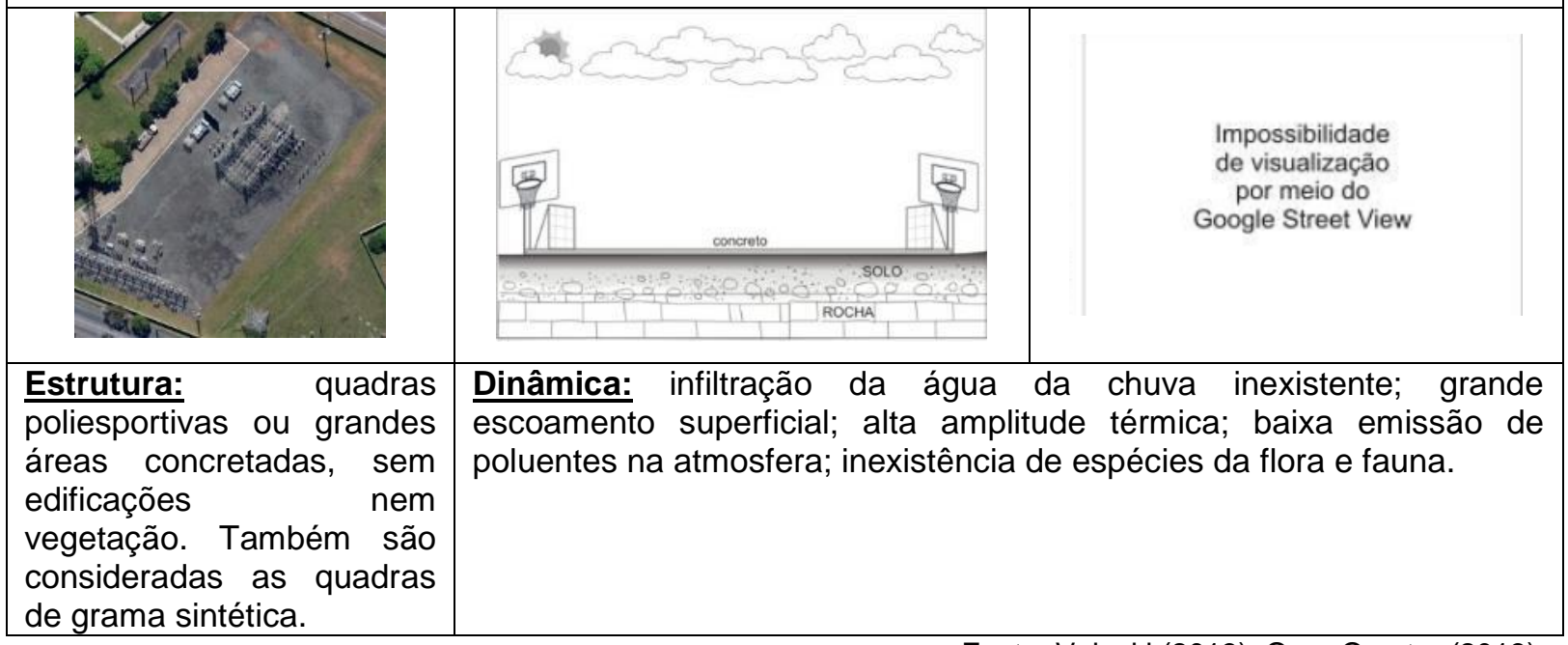

Fonte: Valaski (2013). Org.: O autor (2013).

Figura $5 \mathrm{~d}$. Chave classificatória com inferências da dinâmica da paisagem: transporte

Figure 5d. Classificatory key with inferences of landscape dynamics: transport

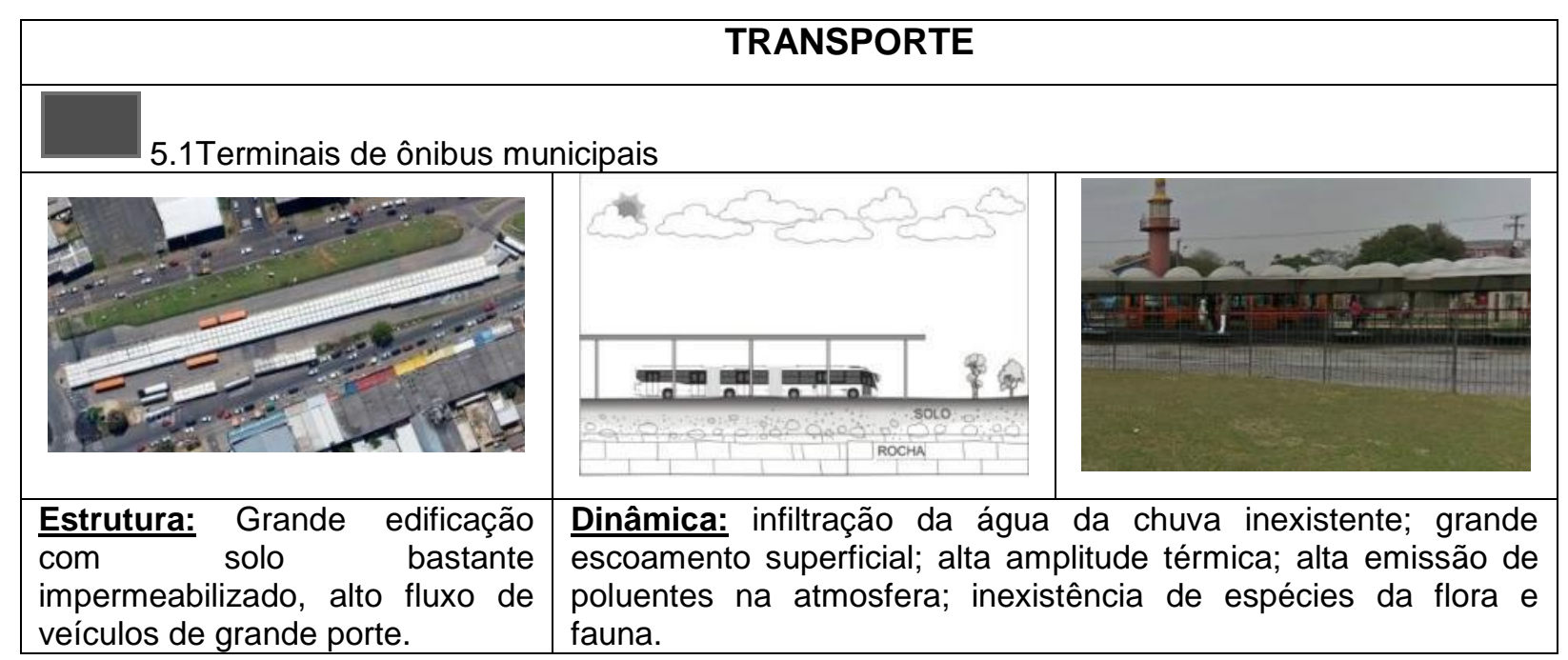

Fonte: Valaski (2013). Org.: O autor (2013).

Vários autores, tais como CAVALHEIRO (1991), DI FIDIO (1985), DOUGLAS (1983), FELLENBERG (1980), MARCUS E DETWYLER (1972), entre outros, citam os benefícios que a vegetação pode proporcionar. Dentre estes benefícios podem ser citados a estabilização de superfícies por meio da fixação do solo pelas raízes das plantas; obstáculo contra vento; proteção da qualidade da água, pois impede que substâncias poluentes escorram para os rios; filtração do ar, diminuindo a poeira em suspensão; equilíbrio do índice de umidade no ar; redução do barulho; proteção das nascentes e dos mananciais; 
abrigo à fauna; organização e composição de espaços no desenvolvimento das atividades humanas; é um elemento de valorização visual e ornamental; estabilização da temperatura do ar; segurança das calçadas como acompanhamento viário; contato com a natureza colaborando com a saúde psíquica do homem; recreação; contraste de texturas, mistérios e riquezas de detalhes; árvores decíduas lembrariam ao homem as mudanças de estação; quebra da monotonia das cidades, cores relaxantes, renovação espiritual; consumo de vegetais e frutas frescas; estabelecimento de uma escala intermediária entre a humana e a construída; caracterização e sinalização de espaços, evocando sua história.

Com a impermeabilização do solo ocorre a redução da infiltração das águas e, consequentemente, um grande aumento do escoamento superficial (runoff). Comumente o sistema de canais entra em colapso, ocorrendo transbordamentos e enchentes (CONTI, 1998). Além disso, o aumento de áreas impermeáveis no meio urbano contribui para a intensificação do fenômeno "ilha de calor".

Em algumas porções do bairro, sobretudo na parte oeste e em um pequeno trecho a sudeste, há algumas quadras de edificações baixas com jardim, e quase nenhuma quadra com edificações baixas com jardim grande. É interessante registrar que uma parte das edificações baixas com jardim ou horta, sobretudo próximas às avenidas, correspondem a prédios de até 4 pavimentos, mostrando que, nesse bairro, a verticalização até esse número de pavimentos pode ser uma boa opção tendo em vista a qualidade ambiental urbana.

Outra situação que merece destaque é a relação existente entre a verticalização e os espaços livres. Nucci (2008) afirma que é oportuno lembrar que o mito, veiculado também por interesses escusos, de que ocorre um ganho de espaços livres à medida que se verticaliza uma certa área é derrubado por Lötsch (1984), demonstrando que acima de quatro andares o ganho de espaços livres é questionável.

Portanto, qualquer verticalização acima de 4 pavimentos acarreta uma crescente pressão sobre os espaços livres, pois na medida em que o edifício vai ganhando altura o espaço construído vai se tornando cada vez maior em relação ao espaço livre (NUCCI, 2008)

Essas considerações indicam que um adensamento do bairro com edificações de até 4 pavimentos liberaria espaços não edificados que poderiam ser ocupados com vegetação e com estruturas para o lazer da população, o que melhoria a qualidade ambiental.

Com relação aos espaços não edificados, cabe ressaltar que o Parque Semeador, localizado na parte leste do bairro, no limite com o bairro Alto Boqueirão, foi classificado como Parques/bosques públicos somente pela denominação, pois apresenta aspectos mais de praça pequena, com vegetação quase exclusivamente herbácea. Aliás, a maior parte das 
praças do bairro recebeu essa classificação, pois muitas delas aparentemente são sobras de terreno (principalmente em beiras de rios) e/ou apresentam, predominantemente, apenas vegetação herbácea, aspectos que corroboram a posição de Buccheri Filho (2012, p. 220) quando afirma que "(...) a criação dos parques (em Curitiba) se deu por outra conotação do que servir aos cidadãos para lazer em primeiro lugar, tendo interesses primários derivados de outras questões" e, também, sua tese de que os Espaços Livres em Curitiba foram implantados segundo um modelo oportunista e não segundo um planejamento sistemático. (BUCCHERI FILHO, 2010)

Em relação ao zoneamento da cidade de Curitiba (CURITIBA, 2000), a lei prevê que no bairro ocorram a Zona Residencial 2 (ZR-2), o Setor Especial Linhão do Emprego (SELE), o Setor Especial de Habitação de Interesse Social (SEHIS), as Zonas de Serviço 1 e 2 (ZS-1 e ZS-2) e a Zona Especial de Serviços (ZES). A localização das Zonas de Serviço ajuda a entender a distribuição das grandes edificações preferencialmente ao longo das rodovias e avenidas mais importantes do bairro (figura 6), pois, de acordo com o Zoneamento da cidade, as Zonas de Serviço localizam-se justamente ao longo de rodovias ou grandes eixos viários, e tem como objetivo abranger as atividades comerciais e de serviços que exigem confinamento em áreas próprias, devido ao seu porte ou natureza, e geram tráfego pesado ou intenso.

Figura 6. Zoneamento do bairro Sítio Cercado

Figure 6. Zoning of Sítio Cercado district

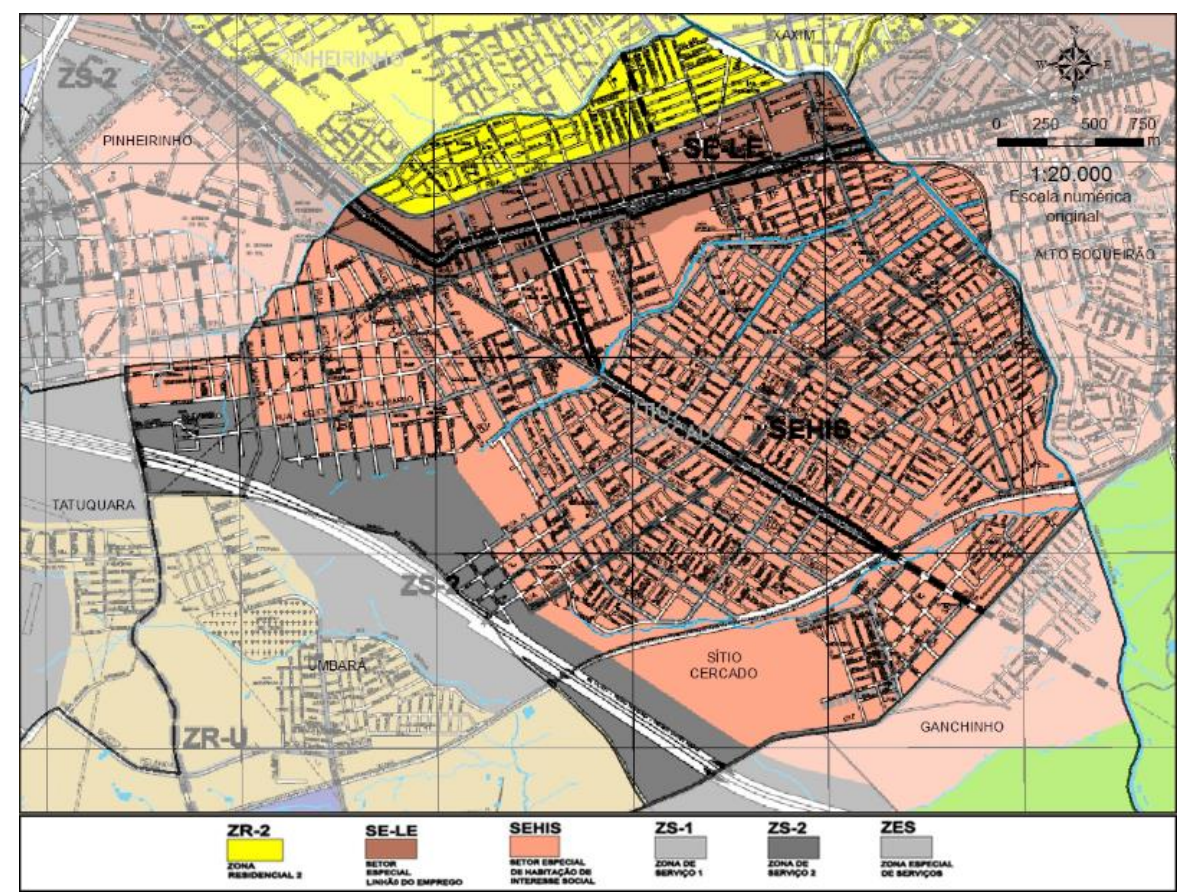

Fonte: Curitiba (2000). Org.: O autor (2015). 
Da mesma forma, o Setor Especial Linhão do Emprego (SE-LE) também explica a relativa concentração de grandes edificações ao norte do bairro, em função de ser uma zona de ocupação mista com predominância de atividades de comércio e indústria com incentivos à geração de emprego e renda (CURITIBA, 2000).

Como é possível observar na figura 6 , a maior parte do bairro é destinada ao Setor Especial de Habitação de Interesse Social (SEHIS), que compreende as áreas "onde há interesse público em ordenar a ocupação por meio de urbanização e regularização fundiária, em implantar ou complementar programas habitacionais de interesse social, e que se sujeitam a critérios especiais de parcelamento, uso e ocupação do solo" (CURITIBA, 2000, p. 8). Nesse setor, é admitida uma área mínima de lote de $180 \mathrm{~m}^{2}$ (na Zona Residencial 2, por exemplo, o lote mínimo estipulado é de $\left.360 \mathrm{~m}^{2}\right)$, além de uma ressalva aos parcelamentos efetuados pela COHAB-CT: nesse caso, o lote mínimo admitido é estabelecido pela legislação federal e municipal de regularização fundiária (CURITIBA, 2000).

Essa redução no tamanho dos lotes, prevista na lei, pode ter contribuído para a falta de vegetação junto às edificações verificada no bairro. A inexistência de vegetação associada à impermeabilização do solo caracteriza um cenário crítico no que se refere à qualidade ambiental.

Devido ao predomínio de edificações baixas sem jardim, ausência de parques e de grandes áreas com vegetação (exceção feita ao fragmento existente ao sul do bairro, que não consta na listagem de áreas verdes disponibilizada pelo IPPUC) e pela grande população que o bairro abriga, o poder público deveria voltar sua atenção para essa região do município, buscando formular estratégias para melhoria da qualidade ambiental, por meio da redução da impermeabilização do solo e aumento da cobertura vegetal. Uma opção poderia ser a arborização das expressivas áreas do bairro ocupadas apenas com vegetação herbácea e arborização de ruas, uma vez que a densa ocupação do bairro dificulta a instalação de grandes áreas com vegetação sem que haja o remanejamento de edificações.

\section{CONCLUSÕES}

Há predominância de edificações baixas (até 4 pavimentos) sem jardim, com solo bastante impermeabilizado no bairro Sítio Cercado. A despeito de as edificações baixas contarem positivamente para a qualidade ambiental, a ausência de vegetação contribui negativamente, apontando uma qualidade ambiental insatisfatória no bairro. Uma das 
possíveis causas para a ausência de vegetação é o tamanho reduzido dos lotes, permitido pelo Zoneamento de Curitiba em grande parte do bairro abrangido pelo Setor Especial de Habitação de Interesse Social (SEHIS). Uma possível solução para esse problema, visando ao aumento da cobertura vegetal do bairro, seria a arborização de ruas, utilizando os jardins frontais das casas, que não podem ser ocupados com construções, além de ocupar com árvores os espaços apenas com vegetação herbácea.

Pelo resultado do mapeamento, pode-se observar que o método desenvolvido por Valaski (2013) é de grande valia na averiguação da qualidade ambiental das áreas urbanizadas, pela possibilidade de espacialização que oferece e por facilitar a interpretação das paisagens com a construção da chave classificatória, em que consta a dinâmica ("funcionamento") das paisagens em função da cobertura do solo existente. Recomenda-se que a pesquisa tenha continuação para a aplicação desse método junto à população, a fim de verificar se realmente há o entendimento das paisagens pela população ou se são necessários mais recursos no intuito de se traduzir com eficácia as informações técnicas e jargões muitas vezes utilizados pelos setores de planejamento.

\section{AGRADECIMENTOS}

Os autores agradecem o apoio financeiro do CNPq pela concessão das bolsas de produtividade em pesquisa ao segundo coautor e de doutorado ao terceiro coautor.

\section{REFERÊNCIAS}

ALBERTI, M. Advances in urban ecology. University of Washington, Seattle, Washington, USA: Springer. 2008.

Ecological Signatures: The Science of Sustainable Urban Forms. Research and Debate. Places, 19(3),p. 56-60. 2007. Disponível em: <http://escholarship.org/uc/item/ 6 nv1x61b>. Acesso em 17/05/2011.

ALMEIDA, J. R. Planejamento Ambiental. Rio de Janeiro: Thex Editora, 1993. 176 p.

ANTUNES, R. L. dos S.; FIGUEIRÓ, A. S. O mapeamento de biótopos como ferramenta para identificação de conflitos ambientais: um estudo de caso na cidade de Santa Maria-RS. REVSBAU, Piracicaba - SP, v.6, n.2, p.1-21, 2011. 
BLANES, L. Análise dos biótopos da bacia hidrográfica do Córrego Águas Espraiadas. 132 f. Dissertação (Mestrado em Geografia) - Departamento de Geografia, Universidade de São Paulo, São Paulo, 2006.

BUCCHERI FILHO, A. T. O planejamento dos espaços de uso público, livres de edificação e com vegetação (EUPLEVs) no município de Curitiba, PR: planejamento sistemático ou planejamento baseado em um modelo oportunista? 2010. Tese (Doutorado em Programa de Pós-graduação em Geografia) - Universidade Federal do Paraná.

BUCCHERI FILHO, A. T. O planejamento dos parques no município de Curitiba, Pr; planejamento sistemático ou planejamento baseado em um modelo oportunista? Caminhos de Geografia, v. 13, n. 41, Uberlândia: UFU, 2012, p. 206-222.

CADAVAL BEDÊ, L.; WEBER, M.; RESENDE, S. R. O.; PIPER, W.; SCHULTE, W. Manual para mapeamento de biótopos no Brasil: base para um planejamento ambiental eficiente. 2 ed. Belo Horizonte: Fundação Alexander Brandt, 1997. 180 p.

CAVALHEIRO, F. Urbanização e alterações ambientais. In: TAUK, S.M. (Org.) Análise Ambiental: uma visão multidisciplinar. Unesp-Fapesp, São Paulo, 1991, p. 88-99.

CONTI, J. B. Clima e meio ambiente. São Paulo: Atual, 1998, 88 p.

CURITIBA. Lei n. 9.800, de 03 de janeiro de 2000 (Lei de Zoneamento). Disponível em: <http://multimidia.curitiba.pr.gov.br/2010/00084664.pdf>. Acesso em 28/04/2015.

DI FIDIO, M. Architettura del paesaggio: criteri di pianificazione e construzione com numerosi schemi e illustrazioni. Milano, Pirola editore, 1985, 302p.

DOUGLAS, I. The urban environment. Londres: Edward Arnold, 1983, 229p.

FELLENBERG, G. Introdução aos problemas da poluição ambiental. São Paulo, EPUSpringer-Edusp, 1980 (original em alemão de 1977), 196p.

HAMBURGER, D.S.; FORESTI, C. - Utilização de atributos, textura e da morfologia matemática na definição de classes de uso do solo urbano. Revista Brasileira de Ecologia, n. 2, Rio Claro, Sociedade de Ecologia do Brasil, p. 22-35,1997.

IPPUC. 2000. Curitiba em dados. Disponível em: <http://ippucweb.ippuc.org.br/Banco dedados/Curitibaemdados/Curitiba_em_dados_Pesquisa.htm>. Acesso em: 21/10/2013. 
Censo 2010: Análise dos bairros de Curitiba - Densidade populacional. Disponível em: <http://www.ippuc.org.br/mostrarPagina.php?pagina=131>. Acesso em: 21/10/2013.

LÖTSCH, B. - In search of human scale. Garten und Landschaft n. 6, 1984, ed. DGGL, Zeitschrift der Deutschen Gesellschaft für Garten kunst und Landschaftspflege.19-26.

MARCUS, M.G.; DETWYLER, T.R. Urbanization and environment. Bermont/Cal., Duxburg Press, 1972, 286p.

$\mathrm{NUCCI}$, J. C. Qualidade ambiental e adensamento urbano: um estudo de Ecologia e Planejamento da Paisagem aplicado ao distrito de Santa Cecília (MSP). Curitiba: Edição do autor, 2008. e-book. Disponível em: <www.geografia.ufpr.br/laboratorios/labs>. Acesso em 24/10/2013.

PRONSATO, S. A. D. Arquitetura e paisagem: projeto participativo e criação coletiva. 1 ed. São Paulo: Annablume; FAPESP; FUPAM, 2005. 150 p.

SUKOPP, H; BLUME, H.R.; KUNICK, W. - The soil, flora and vegetation of Berlin's waste lands. In: LAURIE, I.C. (Ed.): Nature in cities. Wiley, Chichester, 1979.

VALASKI, S. Estrutura e dinâmica da paisagem: subsídios para a participação popular no desenvolvimento urbano do município de Curitiba-PR. $145 \mathrm{f}$. Tese (Doutorado em Geografia)

- Departamento de Geografia, Universidade Federal do Paraná, Curitiba, 2013. 